\title{
A plausible role for actin gamma smooth muscle 2 (ACTG2) in small intestinal neuroendocrine tumorigenesis
}

\author{
Katarina Edfeldt", Per Hellman, Gunnar Westin and Peter Stalberg
}

\begin{abstract}
Background: Small intestinal neuroendocrine tumors (SI-NETs) originate from the enterochromaffin cells in the ileum and jejunum. The knowledge about genetic and epigenetic abnormalities is limited. Low mRNA expression levels of actin gamma smooth muscle 2 (ACTG2) have been demonstrated in metastases relative to primary SI-NETs. ACTG2 and microRNA-145 (miR-145) are aberrantly expressed in other cancers and ACTG2 can be induced by miR145. The aim of this study was to investigate the role of ACTG2 in small intestinal neuroendocrine tumorigenesis.

Methods: Protein expression was analyzed in SI-NETs $(n=24)$ and in enterochromaffin cells by immunohistochemistry. The cell line CNDT2.5 was treated with the histone methyltransferase inhibitor 3deazaneplanocin A (DZNep), the selective EZH2 inhibitor EPZ-6438, or 5-aza-2'-deoxycytidine, a DNA hypomethylating agent. Cells were transfected with ACTG2 expression plasmid or miR-145. Western blotting analysis, quantitative RT-PCR, colony formation- and viability assays were performed. miR-145 expression levels were measured in tumors.

Results: Eight primary tumors and two lymph node metastases displayed variable levels of positive staining. Fourteen SI-NETs and normal enterochromaffin cells stained negatively. Overexpression of ACTG2 significantly inhibited CNDT2.5 cell growth. Treatment with DZNep or transfection with miR-145 induced ACTG2 expression (>10-fold), but no effects were detected after treatment with EPZ-6438 or 5-aza-2'-deoxycytidine. DZNep also induced miR-145 expression. SI-NETs expressed relatively low levels of miR-145, with reduced expression in metastases compared to primary tumors.
\end{abstract}

Conclusions: ACTG2 is expressed in a fraction of SI-NETS, can inhibit cell growth in vitro, and is positively regulated by miR-145. Theoretical therapeutic strategies based on these results are discussed.

Keywords: SI-NET, ACTG2, miR-145, Epigenetic regulation

\section{Background}

Small intestinal neuroendocrine tumors (SI-NETs) are small, slow growing neoplasms that originate from the enterochromaffin cells in the ileum and jejunum. These rare tumors have an incidence about 1 case per 100000 . Metastases have often already occurred at time of diagnosis and the 5-year survival rate is around $65 \%$. Due to excess of tumor-secreted hormones; e.g. serotonin and tachykinins, patients can suffer from the carcinoid syndrome, causing cutaneous flushing, diarrhea, carcinoid

* Correspondence: katarina.edfeldt@surgsci.uu.se

Department of Surgical Sciences, Uppsala University, Uppsala University Hospital, Entrance 70, 1 tr, SE-75185 Uppsala, Sweden heart disease and bronchoconstriction [1, 2]. The WHO classification from 2010 divides small intestinal neuroendocrine neoplasms in three grades; G1-NETs (Ki67 < $3 \%$ ), G2-NETs (Ki67 3-20 \%) and NEC (neuroendocrine carinomas, Ki67 > $20 \%$ ) [3]. SI-NETs (G1 and G2) are most often resistant to chemotherapy and radiation, and medical treatment is limited. Symptom relief can be obtained by somatostatin-analogues and interferon treatment. There is a great need of new therapeutic options that could be beneficial to the patients.

The knowledge of common genetic or epigenetic abnormalities is limited in SI-NETs. Loss of chromosome 
18 is most frequently seen, but no tumor-associated mutations have been found on chromosome 18 [4-6]. A putative role for $T C E B 3 C$ (elongin A3), located at 18q21, as tumor suppressor gene in SI-NETs was recently suggested [7]. The mutation rate is overall low [8], and recently, exome- and genome sequencing found $C D K N 1 B$ to be mutated in $\sim 9 \%$ of SI-NETs [9], implicating importance for this gene in tumorigenesis.

We have previously observed expression of actin gamma smooth muscle 2 (ACTG2) mRNA in a collection of primary SI-NETs, compared to undetectable expression levels in lymph node metastases [10]. Actin proteins are involved in multiple intracellular processes, including maintenance of the cytoskeleton and cell motility [11], and ACTG2 is normally found in enteric tissue. Aberrant expression has been described in several different cancer types and this can affect chemotherapy sensitivity [12-14]. Lower expression levels of ACTG2 were detected in normal colon tissue compared to colon carcinoma [15]. High expression levels of ACTG2 have been associated with improved disease-specific survival [16], and also with a more aggressive phenotype [17, 18]. Furthermore, microRNA-145 (miR-145) can positively regulate expression of $A C T G 2[19,20]$, and overexpression of this microRNA inhibits cell proliferation, cell invasion, tumor growth and can induce apoptosis in other cancer cell types [19, 21].

The aim of this study was to investigate a possible role of ACTG2 in small intestinal neuroendocrine tumorigenesis.

\section{Methods}

\section{Tumor material and cell line}

The patients included in the study $(n=28)$ were all diagnosed with SI-NET in the ileum and operated on at Uppsala University Hospital. This study was approved by the regional ethical review board in Uppsala (11-375/ 1.1.2011, Local ethical vetting board in Uppsala (Regionala etikprövningsnämnden i Uppsala)). Written informed consent for participation and publication of individual clinical details was obtained from all patients. All patients were above 18 years of age at time of inclusion. Fifteen tumors were classified as G1 NETs and 13 as G2 NETs. Patient characteristics are summarized in Additional file 1: Table S1. The tumors were snap frozen in liquid nitrogen and kept at $-70{ }^{\circ} \mathrm{C}$.

A SI-NET cell line, CNDT2.5, developed from a liver metastasis from a patient diagnosed with primary ileal SI-NET [22], was used in the experiments. These cells expressed neuroendocrine markers and somatostatin receptor 2 and responded to synthetic somatostatin analogue (octreotide) treatment [22, 23], although skepticism regarding the neuroendocrine authenticity of this cell line has also been raised [24]. The growth medium for CNDT2.5 was DMEM-F12 complemented with $10 \%$ fetal bovine serum
(Sigma Aldrich), $1 \%$ vitamins, $1 \%$ L-glutamine, $1 \%$ sodium pyruvate, $1 \%$ nonessential amino acids and $1 \%$ PEST (penicillin-streptomycin), and the cells were cultured at $37{ }^{\circ} \mathrm{C}$ in $5 \% \mathrm{CO}_{2}$.

\section{Immunohistochemistry}

Immunohistochemistry procedure is described in detail in previous research $[25,26]$. Paraffin embedded tumor tissue $(n=24)$ sections $(5 \mu \mathrm{m})$ were passed through descending alcohol concentrations and distilled water. Background staining was blocked with $3 \%$ hydrogen peroxide and heated in citrate buffer. The tissues were treated with normal serum from goat (S-1000, Vector) and two different rabbit polyclonal anti-ACTG2 antibodies (NB100-91649 Novus Biologicals, diluted 1/200, and TA313418 Origene, diluted 1/80) and anti-chromogranin A antibodies (Ab-1, LK2H10, NeoMarkers, diluted 1/1000) were used and incubated. A biotinylated secondary antibody from goat anti-rabbit (BA-100 Vector, diluted 1/200) was added to the tissues and then treated with $\mathrm{ABC}$ complex. Visualization was done with DAB color reagent. Absence of primary antibody was used as a negative control. Consecutive sections from each tumor were incubated with anti-ACTG2 and anti-chromogranin A antibody. Also, consecutive sections of normal intestinal mucosa were treated with anti-ACTG2 (NB100-91649 Novus Biologicals, diluted 1/200) and anti-chromogranin A antibodies (Ab-1, LK2H10, NeoMarkers, diluted 1/1000).

\section{Immunofluorescence}

Double immunofluorescence staining was done on sections of intestinal mucosa. Paraffin-embedded sections were deparaffinized, hydrated and subjected to pretreatment (microwave heating for $10 \mathrm{~min}$ at $800 \mathrm{~W}$, followed by $20 \mathrm{~min}$ at $450 \mathrm{~W}$ in citrate buffer, $\mathrm{pH} 6.0$ ). The sections were blocked with normal goat serum (S1000 , Vector) for $30 \mathrm{~min}$ before incubation with primary antibody anti-chromogranin A (Ab-1, LK2H10, NeoMarkers, diluted 1/1000) for $90 \mathrm{~min}$, followed by secondary antibody Alexa Fluor 488 goat anti-mouse for $30 \mathrm{~min}$. Then, incubation with the next primary antibody antiACTG2 (NB100-91649 Novus Biologicals), for $90 \mathrm{~min}$, was followed by the secondary antibody Alexa Fluor 594 goat anti-rabbit, for $30 \mathrm{~min}$ (Life Technologies). The sections were mounted with Vectashield with DAPI (Vector Laboratories Inc.) and evaluated under light microscope.

\section{Western blotting analysis}

Proteins were extracted from tumors or CNDT2.5 cells using Cytobuster ${ }^{\mathrm{TM}}$ protein extraction reagent (Novagen) supplemented with Complete mini protease inhibitor cocktail tablets (Roche Diagnostics). Analysis of ACTG2 in tumor tissue was done using a primary antibody; anti-actin gamma2 (NB100-91649). Anti-Actin antibody (sc 1616, 
Santa Cruz) or coomassie blue was used as loading controls, and for verification of transfection results a mouse monoclonal anti-DDK antibody (TA50011, Origene) was used. After incubation with the appropriate secondary antibody, bands were visualized using the enhanced chemiluminescence system (GE Healthcare).

\section{Quantitative real-time RT-PCR}

For extraction and purification of RNA, RNeasy Plus Mini Kit (Qiagen) was used according to manufacturer's instructions, and for microRNA, miRNeasy Mini Kit (Qiagen) was used. Quantity was measured using NanoDrop. Reverse transcription of DNA-free RNA with random hexamer primers was performed using the "First strand cDNA Synthesis kit" according to manufacturer's instructions (Fermentas) or MicroRNA RT kit (Life Technologies) using 10 ng RNA. Successful DNase I treatment of all RNA preparations was established by PCR analysis of the MYC promoter. qRT-PCR reactions were performed on the Step I qRT-PCR system (Applied Biosystems) using TaqMan Gene Expression Master Mix and assays for ACTG2 (Hs00242273_m1), GAPDH (Hs02758991_g1), hsa-miR145 (002278) and RNU48 (001006) (Applied Biosystems). All samples were amplified in triplicates, and non-template controls were included. Each sample's mean threshold value was corrected for the corresponding mean value for GAPDH mRNA or RNU48 miRNA, used as endogenous controls.

\section{Drug treatment}

CNDT2.5 cells were seeded onto 6 well plates and treated with different concentrations of 5-aza-dC (5-aza2'-deoxycytidine, Sigma Chemical Co., St. Louis, MO, USA, A3656) $(0.025,0.5,1.0,1.25,1.5 \mu \mathrm{M})$ and DZNep (3-deazaneplanocin A, 2.5, 5.0, 10.0, 12.5, $15 \mu \mathrm{M}$ ) and cell viability was accessed using WST-1 (Roche Diagnostics $\mathrm{GmbH})$. Not toxic concentrations were chosen; $1 \mu \mathrm{M}$ for 5-aza-dC and $10 \mu \mathrm{M}$ DZNep. Freshly prepared 5-aza-dC was used in the experiments. DZNep was kindly provided by Dr. Victor Marques [27].

$2 \times 10^{5}$ CNDT2.5 cells were seeded onto 6 well plates. After $24 \mathrm{~h} 10 \mu \mathrm{M}$ DZNep or $1 \mu \mathrm{M} 5$-aza-dC was added in triplicates or 1, 2.5, or $5 \mu \mathrm{M}$ EPZ-6438 (Selleckchem, Houston, TX, USA), a specific EZH2 inhibitor [28], was added to the wells and fresh medium and compounds were added every $24 \mathrm{~h}$. The cells were harvested after 72 h, 96 h for EPZ-6438 treated cells, for RNA preparations. The DZNep treatment was repeated three times and 5-aza-dC and EPZ-6438 twice.

\section{miR-145 analysis}

CNDT2.5 cells $\left(1 \times 10^{5}\right)$ were distributed onto 6 well plates. After $24 \mathrm{~h}$ hsa-miR-145 or negative control miR (mirVana ${ }^{\text {TM }}$ miRNA mimics, Ambion) was transfected in triplicates using $20 \mathrm{mM}$ miRNA and $8 \mu \mathrm{l}$ INTERFERin siRNA transfection reagent (Polyplus Transfection). The cells were harvested and RNA prepared after $72 \mathrm{~h}$. Transfections were repeated three times and successful transfection was determined by qRT-PCR using miR-145 assay. Apoptosis was measured in transfected cells using the Cell Death Detection ELISA kit (Roche Molecular Biochemicals), and as a positive control cells were incubated with $0.1 \mu \mathrm{g} / \mathrm{ml}$ Camptothecin (Sigma-Aldrich), a specific inhibitor of DNA topoisomerase I that induces apoptosis.

Frozen tumor sections from 24 tumors; 8 primary tumors, 9 lymph node metastases and 7 liver metastasis, were when needed macro-dissected to obtain at least $80 \%$ tumor cells (in most cases more than $90 \%$ ) and RNA was extracted using TriZol reagent (Invitrogen), according to manufacturer's instructions. cDNA synthesis followed by qRT-PCR was performed as described above.

\section{Proliferation and viability assays}

A colony formation assay was performed and repeated three times; CNDT2.5 cells $\left(1 \times 10^{5}\right)$ were seeded onto 6 well plates and transfected with $4 \mu \mathrm{g} A C T G 2$-plasmid expression vector using $8 \mu \mathrm{l}$ Lipofectamine 2000 reagent (Life Technologies) according to manufacturer's instructions. The ACTG2 expression vector consisted of an expression-validated cDNA in pCMV6-Entry (TrueORF Gold, catalog no. RC203151. Origene Technologies, Inc., Rockville, MD, USA) and empty pcDNA3.1 was used as control. Six hours after transfection fresh medium was added complemented with $1 \%$ PEST and $0.2 \mathrm{mg} / \mathrm{ml} \mathrm{Ge}-$ neticin (G418, Sigma Aldrich). After 24 h 2000 cells were distributed onto 6 well plates and fresh medium with $0.2 \mathrm{mg} / \mathrm{ml}$ Geneticin was added every $72 \mathrm{~h}$. After 8 days in selection the cells were fixed with $10 \%$ acetic acid/10\% methanol, stained with $0.4 \%$ crystal violet, and visible colonies were photographed and counted. Successful transfection was verified by western blotting after $24 \mathrm{~h}$.

To analyze effect of ACTG2 on viability, CNDT2.5 cells were transiently transfected and 1000 cells were seeded in a 96 well plate in triplicates. After $72 \mathrm{~h}$ cell viability was measured using the cell proliferation reagent WST-1 (Roche Diagnostics $\mathrm{GmbH}$ ) according to manufacturer's instructions.

\section{Statistical analysis}

All data are presented as arithmetical mean \pm standard deviation. Unpaired $t$ test was used for statistical analysis and $p<0.05$ was considered significant.

\section{Results}

ACTG2 protein is variably expressed in $\mathbf{4 2} \%$ of analyzed SI-NETS

Protein expression was evaluated in 24 tumor sections from 17 patients; 16 primary tumors and 8 lymph node 
metastases (Additional file 1: Table S1). Fourteen tumors displayed no staining in the tumor cells (Fig. 1a) and six tumors were positive in small areas of the section (Fig. 1b). Furthermore, two tumors displayed larger areas of positive staining and two tumors were weakly positive in all of the tumor cells (Fig. 1c). No staining was detected in absence of primary antibody (Fig. 1d). In total, eight primary tumors and two lymph node metastases (10 out of 24; $42 \%$ ) displayed positive staining for ACTG2 in SI-NET cells (i.e. chromogranin-positive cells, data not shown). Connective tissue showed mostly positive staining in 19 tumors (Fig. 1a), four displayed mostly negative staining, and one tumor section lacked stromal tissue. A different anti-ACTG2 antibody was used and showed very similar results (data not shown). Western blotting analysis for ACTG2 revealed one band in the correct size range in two tumors with strong stromal staining and not in two tumors that showed negative immunohistochemical staining (Fig. 1e). No obvious relations of ACTG2 expression to clinical data were observed (not shown).

\section{ACTG2 protein is not detected in enterochromaffin cells of the normal small intestine}

In order to determine whether ACTG2 is expressed in chromogranin-positive cells of the normal intestinal mucosa (enterochromaffin cells), immunohistochemistry on consecutive tissue sections and also double immunofluorescence were performed. Thorough analysis did not reveal staining of both ACTG2 and chromogranin A in the same cell (Fig. 2). Since these enterochromaffin cells likely represent founder of SI-NET cells, our results suggest that ACTG2 expression can be induced by unknown mechanisms in a fraction of SI-NETs.

\section{ACTG2 expression is induced by DZNep in vitro}

We next wondered whether ACTG2 expression is controlled by epigenetic mechanisms and whether it could be induced by epigenetic drugs. Treatment of the human SINET cell line CNDT2.5, with the global histone methyltransferase inhibitor 3-deazaneplanocin A (DZNep) but not with the DNA hypomethylating agent 5-aza-2'-deoxycytidine, induced relative ACTG2 mRNA expression approximately 20 -fold (Fig. 3a; data not shown). However, this gene induction did not seem to involve the histone methyltransferase EZH2, which methylates histone 3 lysine 27 and is inhibited by DZNep, since treatment with the specific EZH2 inhibitor EPZ-6438 failed to induce ACTG2 (Fig. 3b). Thus, ACTG2 expression can be controlled directly or indirectly by mechanisms related to DZNep treatment, but other than EZH2 repression. It should be noted that positive controls for treatments with 5-aza-dC and EPZ-6438 were not included here.

\section{Involvement of miR-145}

Expression of $A C T G 2$ is known to be positively regulated by miR-145 in other cell types, and this was also observed ( 12-fold) in CNDT2.5 cells transiently transfected by miR-145 (Fig. 4a). The level of miR-145 was increased more than 1000-fold in transfected cells, as determined by quantitative RT-PCR (data not shown). Interestingly, the expression of miR-145 was induced by DZNep treatment ( 11-fold) (Fig. 4b). miR-145 is known to induce apoptosis in other cell types, but this was not
A

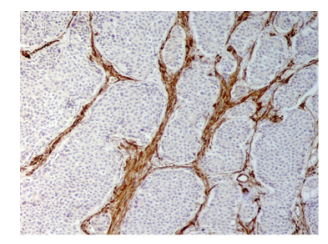

D

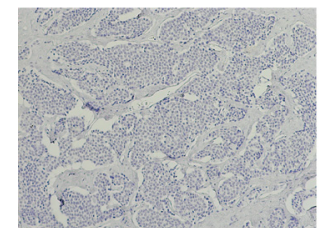

B

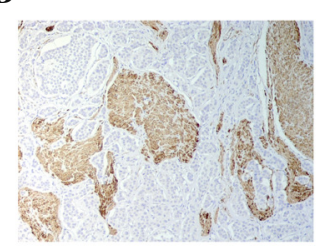

C

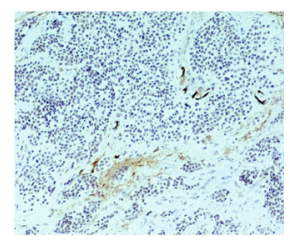

$\mathbf{E}$

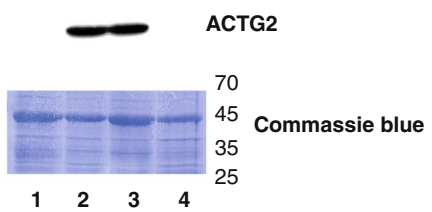

Fig. 1 Analysis of ACTG2 protein expression in SI-NETs by immunohistochemistry (a-d) using ACTG2 antibody (NB100-91649 Novus Biologicals) and western blotting (e) using another ACTG2 antibody (TA313418 Origene). a Negatively stained tumor cells and strong stromal staining (20x). $\mathbf{b}$ Areas with positively stained tumor cells, and negative stromal staining (20x). c Weak staining in all tumor cells (20x). $\mathbf{d}$ No staining in absence of primary antibody (20x). e Western blotting analysis showing antibody specificity and correlation to immunohistochemistry analysis. One band only was visualized in two tumors (lanes 2 and 3) displaying strong stromal staining, and no band was detected in two tumors (lanes 1 and 4) with no staining in both tumor and stromal cells. Lane 1, lymph node metastasis; lanes 2-4, primary tumors. Coomassie blue staining was used as loading control, ladder in $\mathrm{kDa}$ 


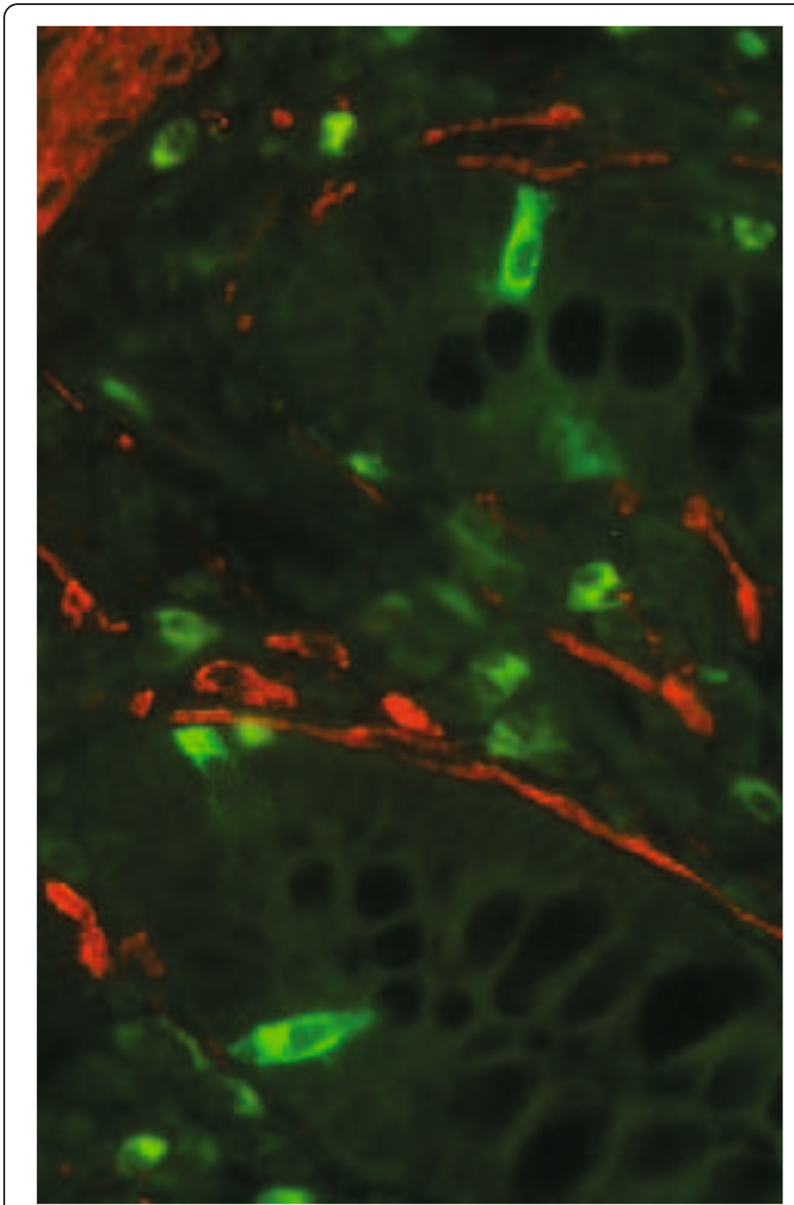

Fig. 2 Double immunofluorescence staining of intestinal mucosa Chromogranin A is visualized as green, showing positively stained enterochromaffin cells. ACTG2 is visualized as red and no staining is detected in chromogranin A positive cells (yellow)
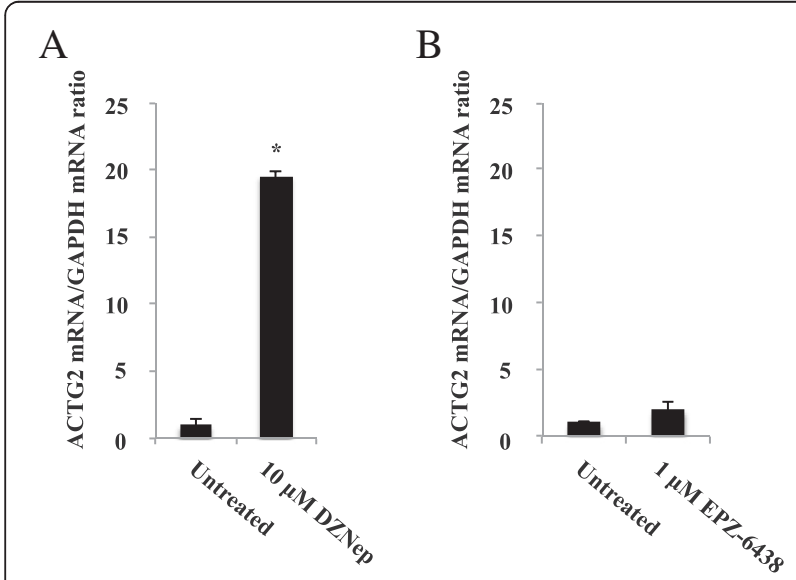

Fig. 3 Effects on ACTG2 mRNA expression in CNDT2.5 cells after DZNep (3-deazaneplanocin A) and 1.0 $\mu \mathrm{M}$ EPZ-6438 treatment, $\mathbf{a}$ and $\mathbf{b}$ respectively observed here (Fig. 4c). Relative miR-145 expression was then determined in 24 SI-NETs; with a mean threshold cycle $(\mathrm{Ct})$-value of 32.4 and somewhat higher expression in 5 primary tumors compared to metastases and CNDT2.5 cells. miR-145 was significantly less expressed in liver metastases compared to primary tumors (Fig. 5a). There was a tendency towards decreased expression in lymph node metastases compared to primary tumors $(p=$ 0.09). This needs to be examined in a larger cohort, although in line with these results, previously published experiments have shown significantly reduced expression of ACTG2 mRNA in lymph node metastases compared to primary tumors (Fig. 5b) [10].

\section{Growth inhibition by $A C T G 2$ in vitro}

To investigate whether ACTG2 could control SI-NET cell growth, a colony formation assay was performed on CNDT2.5 cells stably transfected with an ACTG2 expression plasmid or empty vector. A significantly reduced ability to form colonies (by $32 \%$ ) compared to control cells was observed (Fig. 6a and b). This finding was supported by the reduced viability (Fig. 6c and d), supporting a growth inhibitory effect of ACTG2 in vitro.

\section{Discussion}

ACTG2 is often aberrantly expressed in multiple cancers $[15,17,18]$, and low levels have been associated with worse disease-specific survival [16]. Previously, low mRNA expression levels of ACTG2 were demonstrated in metastases relatively to primary SI-NETs [10]. To investigate a possible role and function of ACTG2 in SINET tumorigenesis this finding was first confirmed by immunohistochemistry, demonstrating absence of protein expression in the majority of investigated SI-NETs. Interestingly, eight primary tumors and two lymph node metastases displayed positive staining for ACTG2 in tumor cells, albeit at variable level and appearance. We could not detect ACTG2 expression in the enterochromaffin cells of the normal intestinal mucosa, suggesting that expression of ACTG2 can be induced at some point during tumor progression representing a dedifferentiated phenotype, rather than being normally expressed in this cell type. Induction of ACTG2 at some point during primary tumor growth may have beneficial effects as ACTG2 showed growth inhibitory effects, at least in vitro. Expression of ACTG2 was detected in stromal cells and whether ACTG2 can display growth effects here remains to be investigated.

This study demonstrated that expression of ACTG2 can be induced by DZNep treatment or miR-145 transfection of the human SI-NET cell line CNDT2.5. Treatment with DZNep also induced expression of miR-145, indicating a possibility that induction of $A C T G 2$ by DZNep may be due to the effects on miR-145 expression. DZNep is a 

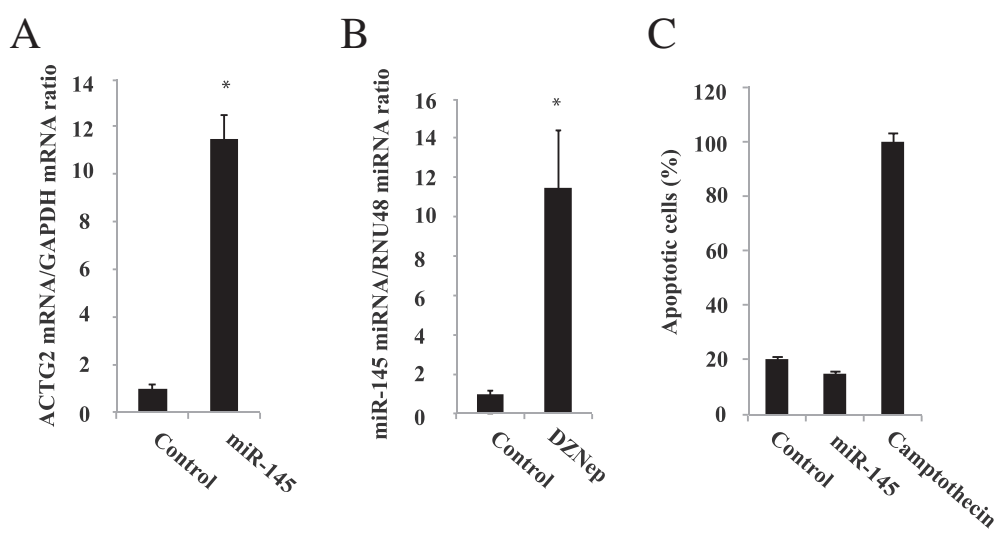

Fig. 4 a Effects on ACTG2 mRNA expression in CNDT2.5 cells after miR-145 transfection. b Effects on miR-145 expression after DZNep treatment. c Quantitative determination of cytoplasmic histone-associated-DNA-fragments (mono- and oligonucleosomes) after miR-145 transfection. Camptothecin at $0.1 \mu \mathrm{g} / \mathrm{ml}$ was used as positive control

potential drug in cancer treatment [29]. DZNep can inhibit the histone methyltransferase EZH2, which is the catalytic subunit of polycomb repressive complex 2 and is responsible for methylation of lysine 27 on histone 3 , a repressive mark [30]. A role of EZH2 was however excluded here since EPZ-6438, a newly developed specific drug inhibiting EZH2 enzymatic activity [28], was not able to induce ACTG2 expression. MiR-145 is often deregulated in cancer cells $[31,32]$ and is known to induce ACTG2 expression in breast cancer [19]. Here, it is demonstrated that this occurs also in SI-NET cells; overexpression of miR-145 increased expression of ACTG2 in vitro. There was a decrease of miR-145 expression in metastasis compared to primary tumors, as observed for ACTG2 [10].
Low levels of ACTG2 are correlated to chemotherapy resistance $[12,14]$ and inducing this gene in SI-NETs would, not only have a growth inhibitory effect, but also potentially make the tumors more sensitive to treatment. SINETs are difficult to cure due to their resistance to chemotherapy and radiation, and new treatment strategies are warranted. MicroRNAs are involved in gene regulation and cancer development, and thus, have a potential role as therapeutic targets. miR-145 has been suggested to be a candidate for RNA medicine in colon tumors with a reduced expression [33]. miR-145 have multiple gene targets, and seems to be able to act as both a tumor suppressor and an oncogene depending on tumor type. Ruebel et al. [34] detected a difference in expression levels
$\mathbf{A}$

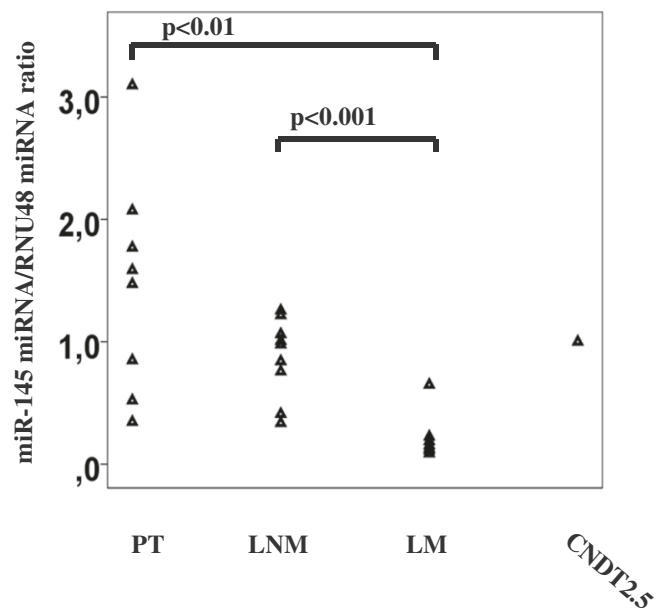

\section{B}

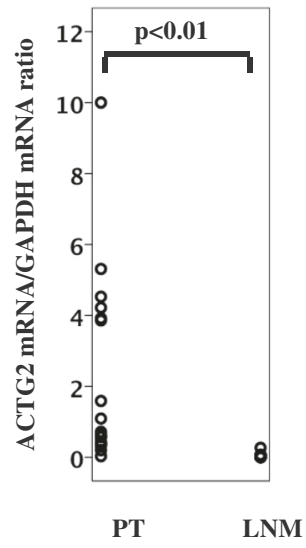

Fig. 5 a miR-145 expression levels in 24 SI-NETs, and in CNDT2.5. A significant $(p<0.01)$ difference between primary tumors and liver metastases, and also between lymph node and liver metastasis $(p<0.001)$ was observed. A tendency towards decreased expression in lymph node metastases compared to primary tumors was detected $(p=0.09)$. b ACTG2 mRNA expression levels in 18 PT and 16 LNM. A significant $(p<0.01)$ difference between primary tumors and lymph node metastases was observed. PT, primary tumor. LNM, lymph node metastasis. LM, liver metastasis 
A

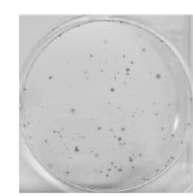

Empty vector

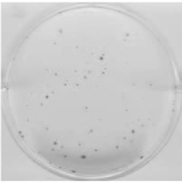

ACTG2

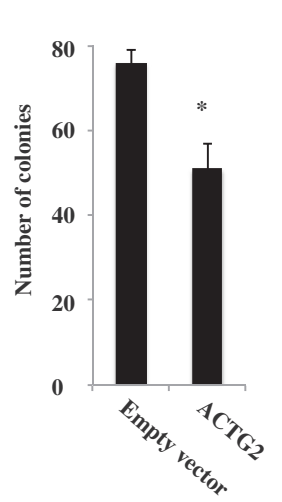

B

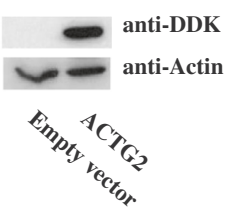

C

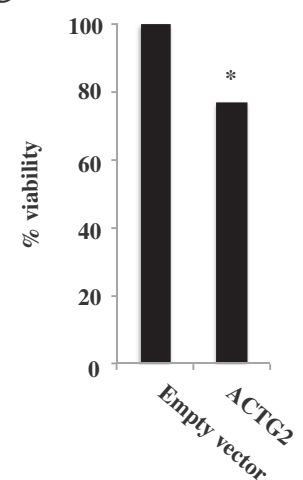

D

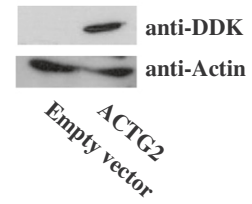

Fig. 6 a Colony formation assay in CNDT2.5 cells stably transfected with a plasmid expressing ACTG2 or with empty expression vector. b Western blotting demonstrating successful transfection of the DDK epitope fused to ACTG2. c Viability assay using WST-1 after transient overexpression of ACTG2. d Western blotting demonstrating successful transfection of the DDK epitope fused to ACTG2

of miR-145 between primary SI-NETs and metastases, and here we confirmed a decrease in expression by tumor progression. These results suggest that miR-145 may be a tumor suppressor and may be important for the ability to metastasize. Inducing or introducing miR-145 may be a potential new therapeutic strategy in SI-NETs.

\section{Conclusions}

Involvement of ACTG2 in small intestinal neuroendocrine tumorigenensis has not been investigated previously. Here, we demonstrate that ACTG2 protein expression can be detected in a fraction of SI-NETs and absent in others, and that it is regulated by miR-145. Overexpression of ACTG2 inhibited cell growth and reduced cell viability in vitro. Further investigation is needed to determine if introducing miR-145 in SI-NETs could have therapeutic advantages.

\section{Ethics and consent to participate statement}

This study was approved by the regional ethical review board in Uppsala (11-375/1.1.2011, Local ethical vetting board in Uppsala (Regionala etikprövningsnämnden i Uppsala)). Written informed consent for participation and publication of individual clinical details was obtained from all patients.

\section{Consent to publish statements}

Written informed consent for participation and publication of individual clinical details was obtained from all patients.

\section{Availability of data and materials statement}

The data is presented in the main manuscript and in an Additional file 1: Table S1.

\section{Additional file}

Additional file 1: Table S1. Patient characteristics,

immunohistochemistry analysis of ACTG2 and miR-145 analysis in SI-NETS (XLSX $49 \mathrm{~kb})$

\section{Competing interest}

The authors declare that they have no competing interests.

Authors' contributions

KE carried out the molecular, cell line and IHC studies and drafted the manuscript. $\mathrm{PH}$ has been involved in revising the manuscript critically for important intellectual content. GW has made substantial contributions to conception and design and interpretation of data. He has been involved in 
revising the manuscript critically for important intellectual content and has given the final approval of the version to be published. PS has been involved in, design and interpretation of data, and revising the manuscript critically for important intellectual content and has given the final approval of the version to be published. All authors have read and approved the final manuscript.

\section{Acknowledgements}

The authors are grateful to B Bondeson and E Persson for skillful technical assistance. The authors thank Dr. Lee Ellis for making the CNDT2.5 cell line available to them.

\section{Funding}

This study was supported Medical Research Council.

Received: 14 July 2015 Accepted: 14 April 2016

\section{Published online: 23 April 2016}

\section{References}

1. Dierdorf SF. Carcinoid tumor and carcinoid syndrome. Curr Opin Anaesthesiol. 2003:16:343-7.

2. Norlen O, Stalberg P, Oberg K, Eriksson J, Hedberg J, Hessman O, et al. Long-term results of surgery for small intestinal neuroendocrine tumors at a tertiary referral center. World J Surg. 2012;36:1419-31.

3. Bosman FT, Carneiro F, Hruban RH, Theise ND. WHO classification of tumours of the digestive system. 2010; (Ed):417.

4. Cunningham JL, Diaz de Stahl T, Sjoblom T, Westin G, Dumanski JP, Janson ET. Common pathogenetic mechanism involving human chromosome 18 in familial and sporadic ileal carcinoid tumors. Genes Chromosomes Cancer. 2011:50:82-94.

5. Kulke MH, Freed E, Chiang DY, Philips J, Zahrieh D, Glickman JN, et al. Highresolution analysis of genetic alterations in small bowel carcinoid tumors reveals areas of recurrent amplification and loss. Genes Chromosomes Cancer. 2008:47:591-603.

6. Lollgen RM, Hessman O, Szabo E, Westin G, Akerstrom G. Chromosome 18 deletions are common events in classical midgut carcinoid tumors. Int J Cancer. 2001;92:812-5.

7. Edfeldt K, Ahmad T, Akerstrom G, Janson ET, Hellman P, Stalberg P, et al. TCEB3C a putative tumor suppressor gene of small intestinal neuroendocrine tumors. Endocr Relat Cancer. 2014;21:2,275-284.

8. Banck MS, Kanwar R, Kulkarni AA, Boora GK, Metge F, Kipp BR, et al. The genomic landscape of small intestine neuroendocrine tumors. J Clin Invest. 2013;123:2502-8

9. Francis JM, Kiezun A, Ramos AH, Serra S, Pedamallu CS, Qian ZR, et al. Somatic mutation of CDKN1B in small intestine neuroendocrine tumors. Nat Genet. 2013;45(12):1483-6.

10. Edfeldt K, Bjorklund P, Akerstrom G, Westin G, Hellman P, Stalberg P. Different gene expression profiles in metastasizing midgut carcinoid tumors. Endocr Relat Cancer. 2011:18:479-89.

11. Pollard TD, Cooper JA. Actin, a central player in cell shape and movement Science. 2009;326:1208-12.

12. Lu X, Pan J, Li S, Shen S, Chi P, Lin H, et al. Establishment of a predictive genetic model for estimating chemotherapy sensitivity of colorectal cancer with synchronous liver metastasis. Cancer Biother Radiopharm. 2009:28:552-8.

13. Watson MB, Lind MJ, Smith L, Drew PJ, Cawkwell L. Expression microarray analysis reveals genes associated with in vitro resistance to cisplatin in a cell line model. Acta Oncology. 2007;46:651-8.

14. Xu CZ, Xie J, Jin B, Chen XW, Sun ZF, Wang BX, et al. Gene and microRNA expression reveals sensitivity to paclitaxel in laryngeal cancer cell line. Int J Clin Exp Pathol. 2013;6:1351-61.

15. Drew JE, Farquharson AJ, Mayer CD, Vase HF, Coates PJ, Steele RJ, et al. Predictive gene signatures: molecular markers distinguishing colon adenomatous polyp and carcinoma. PLoS One. 2014;9(11):e113071.

16. Beck AH, Lee CH, Witten DM, Gleason BC, Edris B, Espinosa I, et al. Discovery of molecular subtypes in leiomyosarcoma through integrative molecular profiling. Oncogene. 2010;29:845-54.

17. Lauvrak SU, Munthe E, Kresse SH, Stratford EW, Namlos HM, Meza-Zepeda $L A$, et al. Functional characterisation of osteosarcoma cell lines and identification of mRNAs and miRNAs associated with aggressive cancer phenotypes. Br J Cancer. 2013;109(8):2228-36.
18. Lin ZY, Chuang WL. Genes responsible for the characteristics of primary cultured invasive phenotype hepatocellular carcinoma cells. Biomed Pharmacother. 2012;66:454-8.

19. Adammek M, Greve B, Kassens N, Schneider C, Bruggmann K, Schuring AN, et al. MicroRNA miR-145 inhibits proliferation, invasiveness, and stem cell phenotype of an in vitro endometriosis model by targeting multiple cytoskeletal elements and pluripotency factors. Fertil Steril. 2013;99(5):1346-55.

20. Gotte M, Mohr C, Koo CY, Stock C, Vaske AK, Viola M. miR-145-dependent targeting of junctional adhesion molecule $A$ and modulation of fascin expression are associated with reduced breast cancer cell motility and invasiveness. Oncogene. 2010;29:6569-80.

21. Akao Y, Nakagawa Y, Naoe T. MicroRNAs 143 and 145 are possible common onco-microRNAs in human cancers. Oncol Rep. 2006;16:845-50.

22. Van Buren 2nd G, Rashid A, Yang AD, Abdalla EK, Gray MJ, Liu W, et al. The development and characterization of a human midgut carcinoid cell line. Clin Cancer Res. 2007;13:4704-12

23. Li SC, Martijn C, Cui T, Essaghir A, Luque RM, Demoulin JB, et al. The somatostatin analogue octreotide inhibits growth of small intestinal neuroendocrine tumour cells. PLoS One. 2012;7, e48411.

24. Ellis LM, Samuel S, Sceusi E. Varying opinoins on the authenticity of a human midgut carcinoid cell line - letter. Clin Cancer Res. 2010;16:5365-6.

25. Björklund P, Åkerström G, Westin G. Accumulation of nonphosphorylated B-catenin and c-myc in primary and uremic secondary hyperparathyroid tumors. J Clin Endocrinol Metab. 2007:92:338-44.

26. Segersten U, Correa P, Hewison M, Hellman P, Dralle H, Carling T, Åkerström G, Westin G. 25-hydroxyvitamin D(3)-1alpha-hydroxylase expression in normal and pathological parathyroid glands. J Clin Endocrinol Metab. 2002; 87:2967-72.

27. Svedlund J, Koskinen Edblom S, Marquez VE, Åkerström G, Björklund P, Westin G. Hypermethylated in cancer 1 (HIC1), a tumor suppressor gene epigenetically deregulated in hyperparathyroid tumors by histone $\mathrm{H} 3$ lysine modification. J Clin Endocrinol Metab. 2012;97:E1307-15.

28. Knutson SK, Warholic NM, Wigle TJ, Klaus CR, Allain CJ, Raimondi A, et al. Durable tumor regression in genetically altered malignant rhabdoid tumors by inhibition of methyltransferase EZH2. Proc Natl Acad Sci U S A. 2013;110:7922-7.

29. Miranda TB, Cortez CC, Yoo CB, Liang G, Abe M, Kelly TK. DZNep is a global histone methylation inhibitor that reactivates developmental genes not silenced by DNA methylation. Mol Cancer Ther. 2009;8:1579-88.

30. Margueron R, Reinberg D. The Polycomb complex PRC2 and its mark in life. Nature. 2011:469:343-9.

31. Akao Y, Nakagawa Y, Naoe T. MicroRNA-143 and -145 in colon cancer. DNA Cell Biol. 2007:26:311-20.

32. Tazawa H, Kagawa S, Fujiwara T. MicroRNAs as potential target gene in cancer gene therapy of gastrointestinal tumors. Expert Opin Biol Ther. 2011; 11:145-55.

33. Kitade Y, Akao Y. MicroRNAs and their therapeutic potential for human diseases: microRNAs, miR-143 and -145, function as anti-oncomirs and the application of chemically modified miR-143 as an anti-cancer drug. J Pharmacol Sci. 2010;114:276-80.

34. Ruebel K, Leontovich A, Stilling G, Zhang S, Righi A, Jin L, et al. MicroRNA expression in ileal carcinoid tumors: downregulation of microRNA-133a with tumor progression. Mod Pathol. 2010;23:367-75.

\section{Submit your next manuscript to BioMed Central and we will help you at every step:}

- We accept pre-submission inquiries

- Our selector tool helps you to find the most relevant journal

- We provide round the clock customer support

- Convenient online submission

- Thorough peer review

- Inclusion in PubMed and all major indexing services

- Maximum visibility for your research

Submit your manuscript at www.biomedcentral.com/submit 